AIAA-2000-2904

\title{
THERMAL CONSIDERATIONS OF SPACE SOLAR POWER CONCEPTS WITH 3.5 GW RF OUTPUT
}

\author{
Michael K. Choi* \\ NASA Goddard Space Flight Center \\ Greenbelt, MD 20771
}

\begin{abstract}
This paper presents the thermal challenge of the Space Solar Power (SSP) design concepts with a 3.5 GW radio-frequency (RF) output. High efficiency klystrons are thermally more favored than solid state (butterstick) to convert direct current (DC) electricity to radio-frequency (RF) energy at the transmitters in these concepts. Using klystrons, the heat dissipation is $0.72 \mathrm{GW}$. Using solid state, the heat dissipation is 2.33 GW. The heat dissipation of the klystrons is $85 \%$ at $500^{\circ} \mathrm{C}, 10 \%$ at $300^{\circ} \mathrm{C}$, and $5 \%$ at $125^{\circ} \mathrm{C}$. All the heat dissipation of the solid state is at $100^{\circ} \mathrm{C}$. Using klystrons, the radiator area is $74,500 \mathrm{~m}^{2}$. Using solid state, the radiator area is $2,362,200 \mathrm{~m}^{2}$. Space constructable heat pipe radiators are assumed in the thermal analysis. Also, to make the SSP concepts feasible, the mass of the heat transport system must be minimized. The heat transport distance from the transmitters to the radiators must be minimized. It can be accomplished by dividing the radiator into a cluster of small radiators, so that the heat transport distances between the klystrons and radiators can be minimized. The area of each small radiator is on the order of $1 \mathrm{~m}^{2}$. Two concepts for accommodating a cluster of small radiators are presented. If the distance between the transmitters and radiators is $1.5 \mathrm{~m}$ or less, constant conductance heat pipes (CCHPs) are acceptable for heat transport. If the distance exceeds $1.5 \mathrm{~m}$, loop heat pipes (LHPs) are needed.
\end{abstract}

\section{INTRODUCTION}

The concept of a Space Solar Power Station (SSPS) using a large photovoltaic solar array in geosynchronous (GEO) orbit around the Earth and transmitting this power to Earth was first proposed by Glaser in 1968.' The SSPS in GEO orbit is stationary with respect to a desired location on Earth. The solar array in geosynchronous orbit could receive up to 15

\footnotetext{
Associate Fellow

' Copyright $\odot 2000$ The American Institute of Aeronautics and Astronautics, Inc. No copyright is asserted in the United States under Title 17, U.S. Code. The U.S. Government has a royaltyfree license to exercise all rights under the copyright claimed herein for Governmental purposes. All other rights are reserved by the copyright owner.
}

times as much solar radiation as that on the ground. ${ }^{2}$

Solar radiation is available in the GEO orbit almost all around the equinoxes when the satellite is shadowed by the Earth for up to 72 minutes per day. ${ }^{3}$ Solar arrays covert solar energy to electricity, which is fed to microwave generators within the transmitting antenna (transmitter) between the two solar arrays. Then the transmitter transmits the energy to a receiving and rectifying antenna, known as "rectenna", on Earth, where the energy is reconverted into electricity.

As part of the SSP Exploratory Research and Technology (SERT) program at the National Aeronautics and Space Administration (NASA), five system design concepts were evaluated in 1999 and early 2000 . They were:

-Dual RF Reflector using klystron transmitter concept. ${ }^{4}$

-Dual RF Reflector using solid state (butterstick) transmitter concept. ${ }^{4}$

-Single RF Reflector using klystron transmitter concept. 5

-Single RF Reflector using solid state (butterstick) transmitter concept. ${ }^{3}$

-Integrated Symmetrical concept using klystron transmitter. ${ }^{6.7}$

The mission life of the SSP concepts is 40 years. Figure 1 shows the Dual RF Reflector concept. The abacus structural frame provides runs for power management and distribution (PMAD) cabling and permits a "plug and play" solar array approach for assembly and maintenance. The concentrated solar arrays always face the Sun with very little shadowing. The solar concentrator uses shifting lens to accommodate seasonal beta-tracking, and eliminates rotational joints between the cells and the abacus frame. The reflector design eliminates massive rotary joint and slip rings of the 1979 concept. The triangular truss structure provides a reasonable aspect ratio for the abacus frame. The solar concentrators convert solar energy to electricity. The DC is converted to RF energy. Two transmitters transmit a total of $3.5 \mathrm{GW}$

1 
of RF to a "rectenna" on Earth. The diameter of each transmitter is $500 \mathrm{~m}$.

Figure 2 shows the single RF Reflector concept. One transmitter transmits $3.5 \mathrm{GW}$ of RF to a "rectenna" on Earth. The diameter of the transmitter is $500 \mathrm{~m}$.

Figure 3 shows the year 1999 version of the Integrated Symmetrical concept. In this concept, 48 primary mirrors of $680-\mathrm{m}$ diameter focus solar radiation to two solar arrays. The total solar energy collected is $13.38 \mathrm{GW}$. The concentration ratio is 3.8:1. The solar arrays generate $4.41 \mathrm{GW}$ of electricity, which is converted to radio-frequency energy by klystrons on the transmitter. The diameter of the each solar array is $1.55 \mathrm{~km}$. The diameter of the transmitter is $1 \mathrm{~km}$. In the year 2000 version (see Figure 4), there are 84 primary mirrors of $500-\mathrm{m}$ diameter. The diameter of each solar array is $1.1 \mathrm{~km}$. The diameter of the transmitter is $500 \mathrm{~m}$.

The thermal analysis in this paper is meant to show the order of magnitude type differences, and is not exact.

\section{RADIATOR SIZING FOR WASTE HEAT FROM CONVERTING DC TO RF}

Sizing of radiators in the SSP concepts using klystrons and solid state (butterstick) are presented below.

\section{Concepts using klystrons}

Using high efficiency klystrons, the efficiency of converting DC electricity to RF is $83 \%$. Therefore, with a $3.5 \mathrm{GW}$ RF output, the DC input is $4.22 \mathrm{GW}$, and the heat dissipation is $0.72 \mathrm{GW}$. A breakdown of the heat dissipation of the klystrons at the transmitters is as follows:

- $85 \%$ at $500^{\circ} \mathrm{C}$.

- $10 \%$ at $300^{\circ} \mathrm{C}$.

- $5 \%$ at $125^{\circ} \mathrm{C}$.

Due to the three very different temperatures, three different radiators are needed for each transmitter. A space constructable heat pipe radiator ${ }^{5}$ is selected in this analysis because it is the most developed concept, and is a proven and reliable technology. The following assumptions are used in the thermal analysis of the radiators:

- One side of the radiators is on the anti-sun side and radiates to space.

- In the GEO orbit, albedo and Earth infrared radiation are neglected.

- Emittance of the radiator, which has white paint as the coating, is 0.9 .

- View factor of radiator to space is $\mathbf{1 . 0}$.

- The backside of the radiator is radiatively isolated from the SSP bus, which is at room temperature.
The radiators sizes required are as follows: - $33,400 \mathrm{~m}^{2}$ at $500^{\circ} \mathrm{C}$.

- $13,000 \mathrm{~m}^{2}$ at $300^{\circ} \mathrm{C}$.

- $28,000 \mathrm{~m}^{2}$ at $125^{\circ} \mathrm{C}$.

The total size of the radiators is $74,400 \mathrm{~m}^{2}$.

Concepts using Solid State (Butterstick)

In the solid state (butterstick) design concept, the efficiency of converting DC electricity to RF is only $60 \%$. Therefore, with a $3.5 \mathrm{GW} \mathrm{RF}$ output, the $\mathrm{DC}$ input is $5.83 \mathrm{GW}$, and the heat dissipation is 2.33 GW. The temperature of the solid state electronics at the transmitter is $100^{\circ} \mathrm{C}$. The radiator area required is $2,362,200 \mathrm{~m}^{2}$, which is 6 times the total area of the two transmitters.

Klystrons are more favored than solid state because the radiator area is 32 times smaller. If both sides of the radiator radiates heat to space, the radiator area is cut by half.

\section{EFFECT OF HEAT TRANSPORT DISTANCE BETWEEN RADIATORS AND TRANSMITTERS}

The mass of the heat transport system from the transmitters to the radiators in the SSP design concepts has a very large impact on the feasibility of these concepts. It is true no matter what heat rejection technology is used. The reason is that heat must be transported to an acceptable location before it can be rejected to space. The heat rejection technologies include space-constructable heat pipe radiator, rotating film radiator, rotating solid radiator, liquid droplet radiator, moving belt radiator, Curie Point radiator, and variable surface area radiator. These advanced radiator technologies were proposed in the 1970s1980s. An assessment of these advanced radiator concepts was made by Juhasz and Peterson. ${ }^{8}$

LHPs have high heat transport capacities. $9,10.11$ They can be used to transport the waste heat from the transmitters to the radiators. The working fluids for the LHPs in the SSP concepts using klystron transmitters are assumed to be the following in the thermal analysis:

- Potassium at $500^{\circ} \mathrm{C}$.

- Thermex at $300^{\circ} \mathrm{C}$.

-Methanol at $125^{\circ} \mathrm{C}$.

The diameter of the LHPs is assumed to be 2.54 $\mathrm{cm}$, and its wall thickness is assumed to be $0.09 \mathrm{~cm}$. The LHPs for $500^{\circ} \mathrm{C}$ and $300^{\circ} \mathrm{C}$ are made of stainless steel. The LHPs at $125^{\circ} \mathrm{C}$ are made of aluminum. Each LHP has a single evaporator and transports $2 \mathrm{~kW}$ of heat from the transmitters to the radiators. Table 1 shows the distribution of the mass. The mass of the heat transport system per unit RF output per unit distance between the transmitter and radiator is 262 metric tons $/ \mathrm{GW} / \mathrm{m}$. A $33 \%$ redundancy is included. 
Figure 1. Dual RF Reflector Concept.

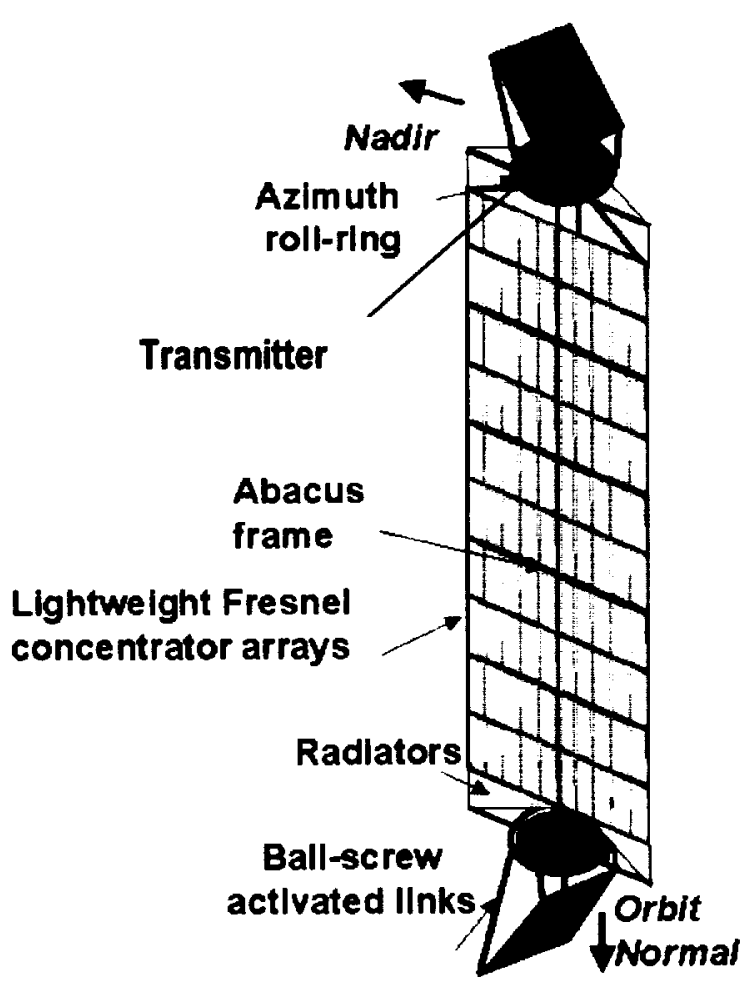

Figure 2. Single RF Reflector Concept.

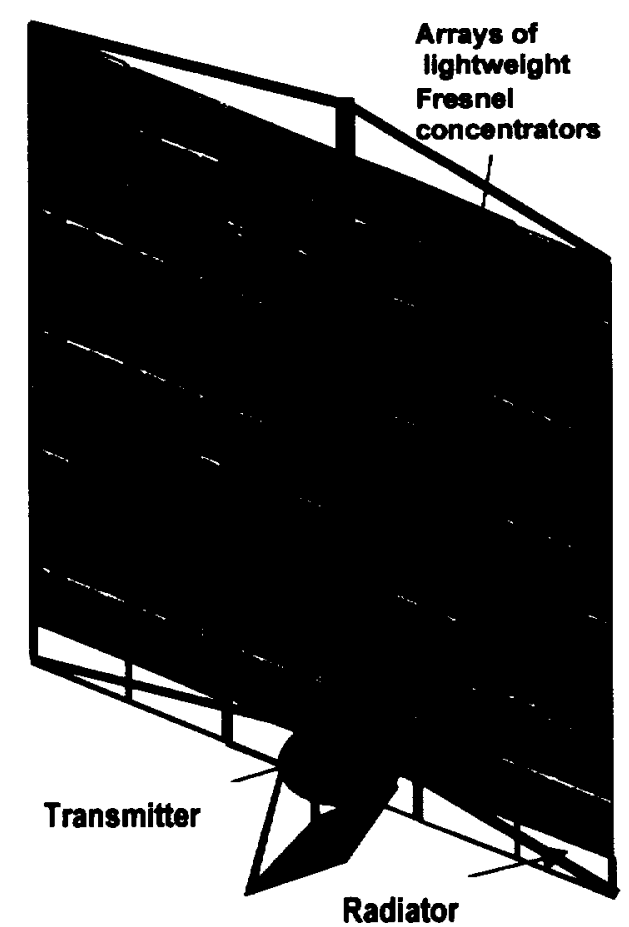

3

American Institute of Aeronautics and Astronautics 
Figure 3. Integrated Symmetrical Concept (1999 Version).

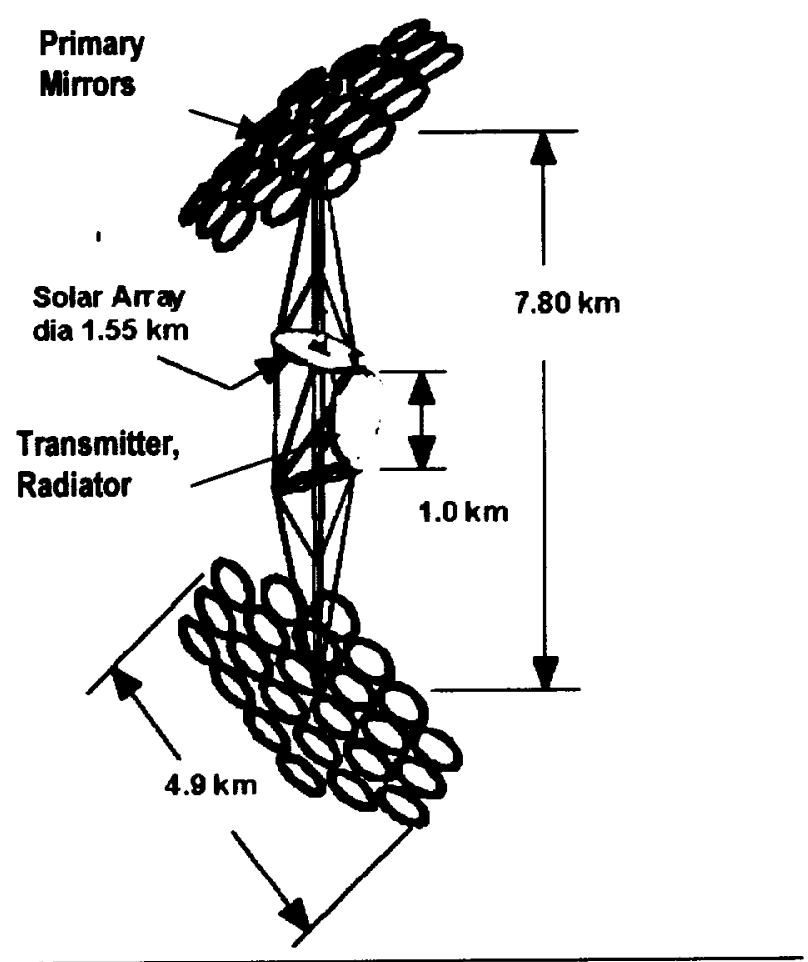

Figure 4. Integrated Symmetrical Concept (2000 Version).

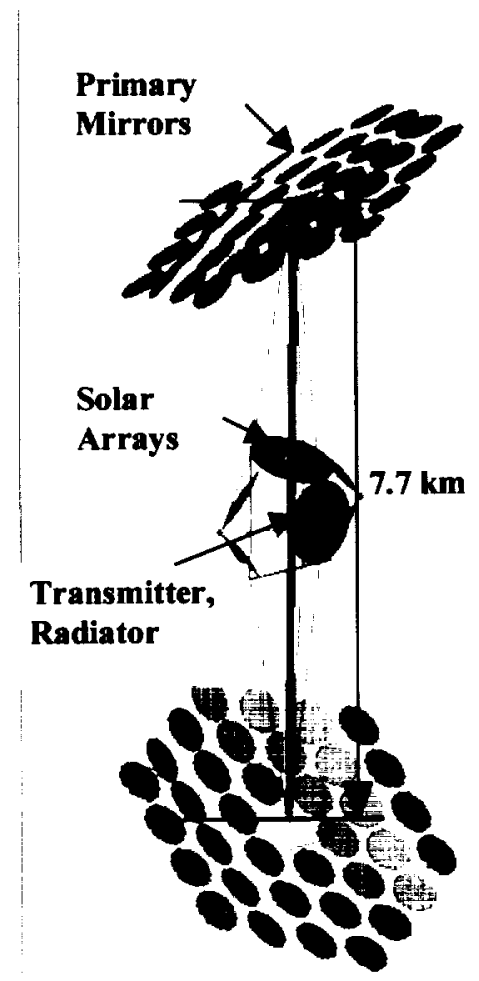


In the solid state (butterstick) concept, the working fluid for the LHPs is assumed to be ammonia, because the operating temperature of the electronics is $100^{\circ} \mathrm{C}$. The diameter of the LHPs is assumed to be $2.54 \mathrm{~cm}$, and its wall thickness is assumed to be 0.09 $\mathrm{cm}$. The LHPs are made of aluminum. Each LHP transports $2 \mathrm{~kW}$ of heat from the transmitters to the radiators. Table 1 shows the distribution of the mass. The mass of the heat transport system per unit RF output per unit distance between the transmitter and radiator is 340 metric tons $/ \mathrm{GW} / \mathrm{m}$. A $33 \%$ redundancy is included.

The baseline RF output of the transmitters is 3.5 GW. In the dual RF reflector concept, the radiator plane is perpendicular to the transmitter plane, and there is a large radiator for each of the two transmitters (see Figure 1). Also, the diameter of the transmitters is $500 \mathrm{~m}$. To transport heat from some of the klystrons across the transmitters to the radiators, the distance is over $250 \mathrm{~m}$. Suppose the average transport distance is $150 \mathrm{~m}$, then the mass of the heat transport system is 103,425 metric tons. It is larger than the mass of all the other components combined in the SSP concept.

In the solid state (butterstick) concept, the mass of the heat transport system is 139,400 metric tons. In the Integrated Symmetrical concept, the radiator is in the same plane as the transmitter. It has the same problem of heat transport distance as in the Dual RF Reflector concept.

To make the mass of the SSP design concepts acceptable, the distance between the transmitters and radiators must be minimized.

\section{PROPOSED RADIATOR CONCEPTS}

As mentioned earlier, several advanced radiator technologies were proposed in the 1970s-1980s. Space constructable heat pipe radiator is selected in the present thermal analysis because it is the most developed concept, and is a proven and reliable technology. Recently, a lightweight carbon-carbon composite prototype radiator was successfully fabricated and tested at NASA Glenn Research Center. ${ }^{13}$ The design operating temperature is 700 to $800 \mathrm{~K}$.

It was also mentioned earlier that for a $3.5 \mathrm{GW}$ RF output, the total heat pipe radiator area required for the SSP concepts using klystrons is $74,470 \mathrm{~m}^{2}$. In the Dual RF Reflector concept, the radiator area required for each transmitter is $37,235 \mathrm{~m}^{2}$, which is $19 \%$ of the area of the $500-\mathrm{m}$ diameter transmitter. The front face of the transmitters transmits RF, and the heat dissipation of the klystrons is on the rear face. The klystrons are scattered on the transmitters. Therefore, locating the radiators at the rear face of the transmitters alone is insufficient to reduce the mass of the heat transport system to within budget. The radiator must be divided into a cluster of small radiators, so that the heat transport distances between the klystrons and radiators are minimized. The area of each small radiator is on the order of $1 \mathrm{~m}^{2}$.

Figure 5 presents the first concept for the location of a cluster of small radiators at the rear surface of the transmitters. All the radiators are $1.5 \mathrm{~m}$ from the transmitter. There is sufficient room for the DC distribution lines and solar array support structure, and for the robots to service the transmitters. The size of each radiator is approximately $1 \mathrm{~m} \times 1 \mathrm{~m}$. Only one side of the radiators views space. The back of radiators faces the transmitters. The heat transport distance is only $1 \%$ of the baseline.

Figure 6 presents the second concept. The minimum distance between the transmitter and radiators is taken to be $1 \mathrm{~m}$, and the maximum distance is taken to be $10 \mathrm{~m}$. There is also sufficient room for the DC distribution lines and solar array support structure, and for the robots to service the transmitters. The height of the radiators is about $0.3 \mathrm{~m}$, and the area is about $1 \mathrm{~m}^{2}$. The radiators are located at cylindrical envelopes. The diameter of the cylindrical envelope closest to the transmitter is the largest. The diameter of the cylindrical envelope farthest from the transmitter is the smallest. With a special arrangement of the radiators, not only the front of the radiators has a good view to space, but also the rear can view space at least partially. The average heat transport distance is only $4 \%$ of the baseline.

In both of these radiator configurations, each radiator is integrated with a number of LHPs or CCHPs to form a modular unit. The mission life is $\mathbf{4 0}$ years, and the design life of heat pipe radiators is shorter. The modular heat pipe radiator units can be replaced by robots in flight when needed.

\section{THERMAL CONSIDERATIONS OF HEAT TRANSPORT METHOD}

Three methods of transporting heat from the transmitters to the radiators are compared. They are heat straps, LHPs, and CCHPs.

\section{Heat Straps}

A thermal analysis of heat straps to transport heat from the transmitters to the radiators was performed. The results are presented in Figures 7 through 9. Figure 7 shows the total cross-section area of heat straps per unit length versus the temperature gradient between the transmitter and radiator. A 
comparison of copper and composite material is also made in Figure 7 . The thermal conductivity of copper is $3.91 \mathrm{~W} / \mathrm{cm}-{ }^{\circ} \mathrm{C}$, and that of composite is $4.87 \mathrm{~W} / \mathrm{cm}-$ ${ }^{\circ} \mathrm{C}$. As the temperature gradient increases, the crosssection area decreases. For a $40^{\circ} \mathrm{C}$ gradient between the transmitter and radiator, the total cross section area of copper heat straps is $45,950 \mathrm{~m}^{2}$ per meter length, and that of composite is $36,800 \mathrm{~m}^{2}$ per meter length.

Figure 8 shows the total mass of heat straps per unit length versus the temperature gradient between the transmitter and radiator. A comparison of copper and composite material is also made in Figure 8 . The density of copper is $8.9 \mathrm{~g} / \mathrm{cm}^{3}$, and that of composite is $1.08 \mathrm{~g}^{\prime} \mathrm{cm}^{3}$. For a $40^{\circ} \mathrm{C}$ gradient between the transmitter and radiator, the total mass of copper heat straps is 412,198 metric tons per meter length, and that of composite is 39,817 metric tons per meter length. Therefore, heat straps are not acceptable to transport as much as $0.717 \mathrm{GW}$ of waste heat from the transmitters to the radiators because they are too heavy.

Figure 9 shows the effect of the radiator temperature on the radiator area required for the $500^{\circ} \mathrm{C}$ klystrons, which contribute $85 \%$ of the total heat dissipation. The radiator area increases when the radiator temperature decreases, that is, when the temperature gradient of the heat straps increases. If the temperature gradient between the transmitter and radiator is neglected, the radiator area required for the $500^{\circ} \mathrm{C}$ klystrons is $37,615 \mathrm{~m}^{2}$. If the temperature gradient is $40^{\circ} \mathrm{C}$, the radiator area increases to 46,522 $\mathrm{m}^{2}$. The mass of the radiators increases when the radiator area increases. This further makes heat straps unacceptable.

Figure 5. First Concept of Cluster of Small Radiators.

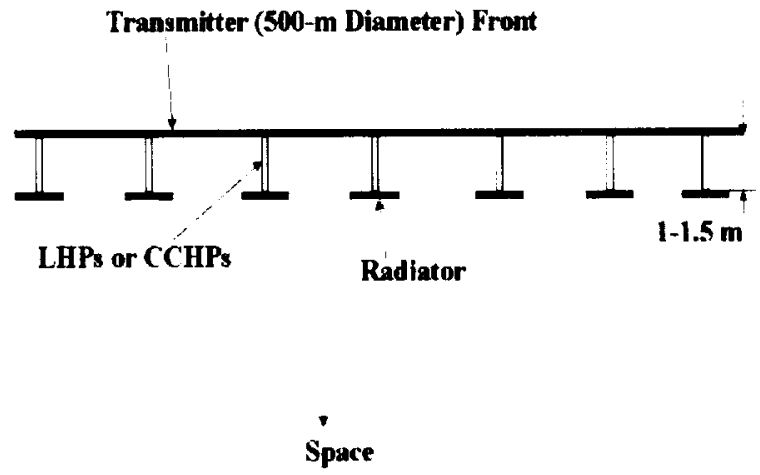

Figure 6. Second Concept of Cluster of Small Radiators.

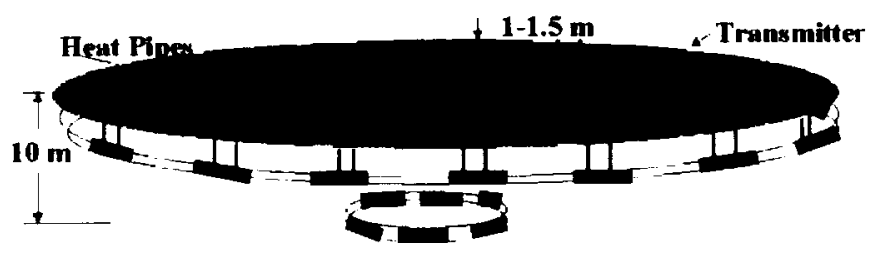

- A Number of Cylindrical Envelopes for Radiators, Largest Near Transmitter, and Smaller Away from Transmitter.

- A Number of Radiators on Surface of Each Cylindrical Envelope.

Figure 7. Cross Section Area of Heat Straps.

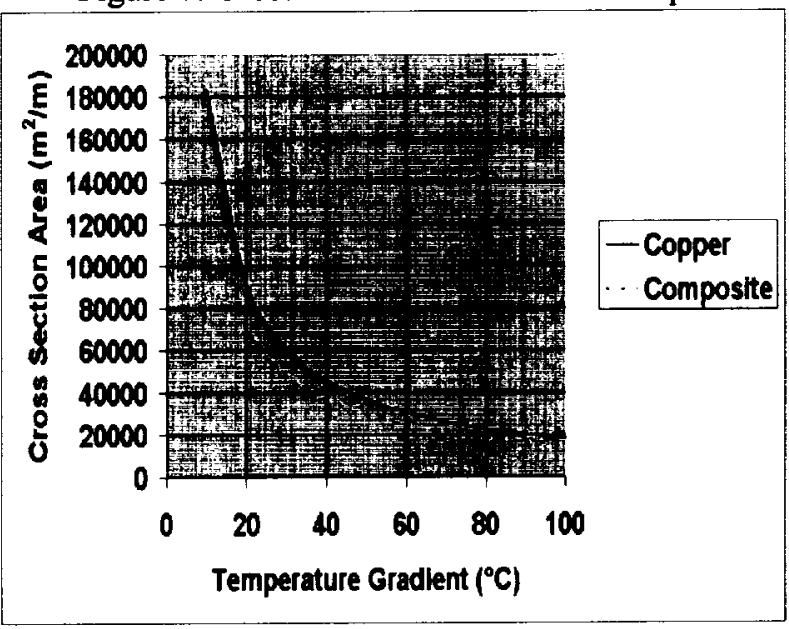

Figure 8. Mass of Heat Straps.

All Radiators Face Same Direction 


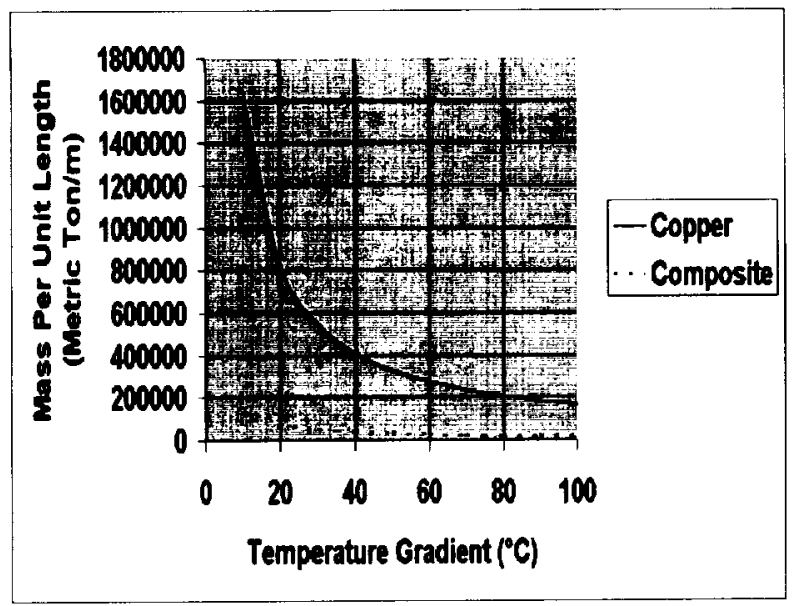

Figure 9. Radiator Area vs. Radiator Temperature for $500^{\circ} \mathrm{C}$ Klystrons.

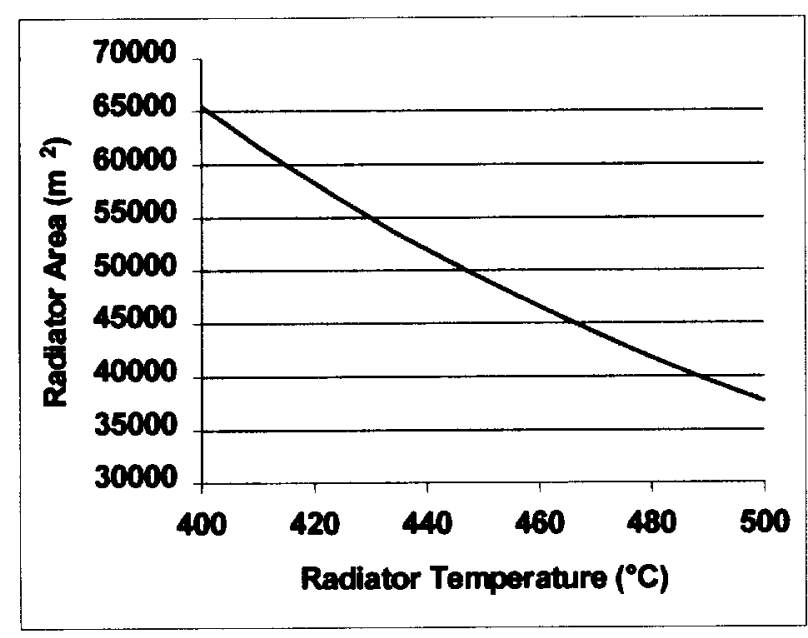

\section{LHPs versus CCHPs}

To reduce the mass of the thermal control system to an acceptable level, LHPs or CCHPs are needed. Basically, there is no temperature gradient within the LHPs or CCHPs. There will be small temperature gradients at the interfaces due to contact resistances. Table 2 below presents the mass of the thermal control system of the transmitters using LHPs in the dual RF reflector concept using klystrons. For a 3.5 GW RF output from the transmitters, the mass of the LHPs is 676 metric tons per meter distance between the transmitter and radiators. If the average distance is $5 \mathrm{~m}$, then the mass of the LHPs is 3,378 metric tons. A $33 \%$ redundancy is included. The mass of the radiator and LHP condensers is 575 metric tons, and that of the evaporator is about 500 metric tons. It is assumed that the radiators are made of carbon-carbon composite. A 1.0 view factor to space is assumed for all the radiators.
Table 2 also presents the mass of the thermal control system of the transmitters using CCHPs in the dual RF reflector concept using klystrons. For a 3.5 GW RF output from the transmitters, if the distance between the transmitter and radiators is $1 \mathrm{~m}$, the mass of the heat pipes is 1,423 metric tons per meter distance. The total mass of heat pipes is 1,423 metric tons. If the heat transport distance increases, the heat transport capacity of the CCHPs decreases, assuming the outer diameter of the CCHPs to be $2.54 \mathrm{~cm}$ (1 inch). The product of the heat transport capacity and transport distance is taken to be $1.37 \mathrm{~kW}-\mathrm{m}$. If the distance between the transmitter and radiators is $5 \mathrm{~m}$, the mass of the LHPs is 7,116 metric tons per meter distance, and the total mass is 35,576 metric tons. A $33 \%$ redundancy is included.

For CCHPs to be acceptable, the distance between the transmitters and radiators is limited to about $1 \mathrm{~m}$ to $1.5 \mathrm{~m}$. The mass of the radiator integrated with heat pipes is $\mathbf{5 7 5}$ metric tons. There is no separate mass for the evaporators.

The differences between LHPs and CCHPs are as follows. The wicks of LHPs are located at the evaporators, but the wicks of CCHPs are located along the entire length of the heat pipes. The heat transport capacity of LHPs is independent of the heat transport distance, but that of CCHPs is strongly dependent on the heat transport distance. During startup, based on the current technology, the entire length of the LHPs needs to be heated by heaters, for example, to melt the working fluid from solid to liquid. It would require about $30 \mathrm{GJ}$ of thermal energy, or $0.8 \mathrm{MW}$ of heater power for ten hours, in the system shown in Table 1. The SSP needs to provide this heater power. The heater power is needed at startup only. The heaters can be kapton film heaters bonded to the exterior of the LHPs. Heating at startup is not needed for CCHPs because there are wicks along the entire CCHPs.

Currently, the maximum operating temperature in the heat pipe technology is under $200^{\circ} \mathrm{C}$ (water). For LHPs to operate in the $300^{\circ} \mathrm{C}$ to $500^{\circ} \mathrm{C}$ range, liquid metal is required. This high temperature LHP technology has not been developed, but could potentially be developed for SSP by 2020 .

Liquid metal CCHP technology is an existing technology. Liquid metal CCHPs were made and operated successfully as early as 1973. Recently, NASA Glenn Research Center has successfully fabricated and tested carbon-carbon composite prototype liquid potassium heat pipe radiators. ${ }^{13}$ Liquid metal LHP technology is not an existing technology, mainly because there is no demand for it. Using the LHP technology and liquid metal heat pipe 
technology, it is feasible to develop liquid metal LHP technology.

Figures 10 and 11 present the mass and number of CCHPs, respectively, versus the distance between the transmitter and radiators. The product of heat transport capacity and transport distance for the CCHPs, which have a $2.54 \mathrm{~cm}$ (1 inch) outer diameter, is taken to be $1.37 \mathrm{~kW}-\mathrm{m}$.

The CCHPs or LHPs and radiator form an integral unit. The radiator temperature is uniform. Although the radiators are small, while compared to a single radiator of $30,000 \mathrm{~m}^{2}$ or larger, they are still on the order of $1 \mathrm{~m}^{2}$. Using LHPs or CCHPs, the temperature gradient between the transmitters and radiators is much less than that of heat straps, and its effect on the size of the radiators is smaller.

Figure 10. Mass of CCHPs to Tansport $0.72 \mathrm{GW}$ of Waste Heat vs. Distance Between Transmitter and Radiator (Redundancy Not Included).

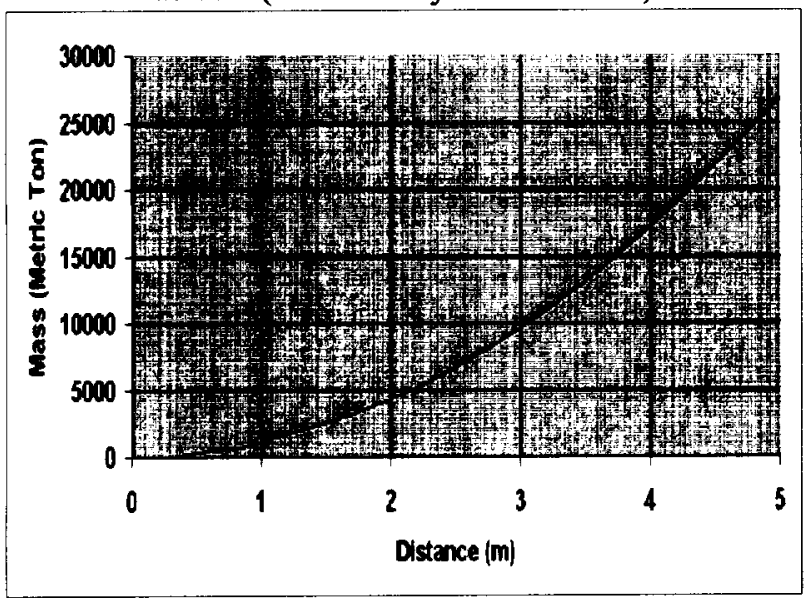

Figure 11. Number of CCHPs to Tansport $0.717 \mathrm{GW}$ of Waste Heat vs. Distance Between Transmitter and Radiator (Redundancy Not Included).

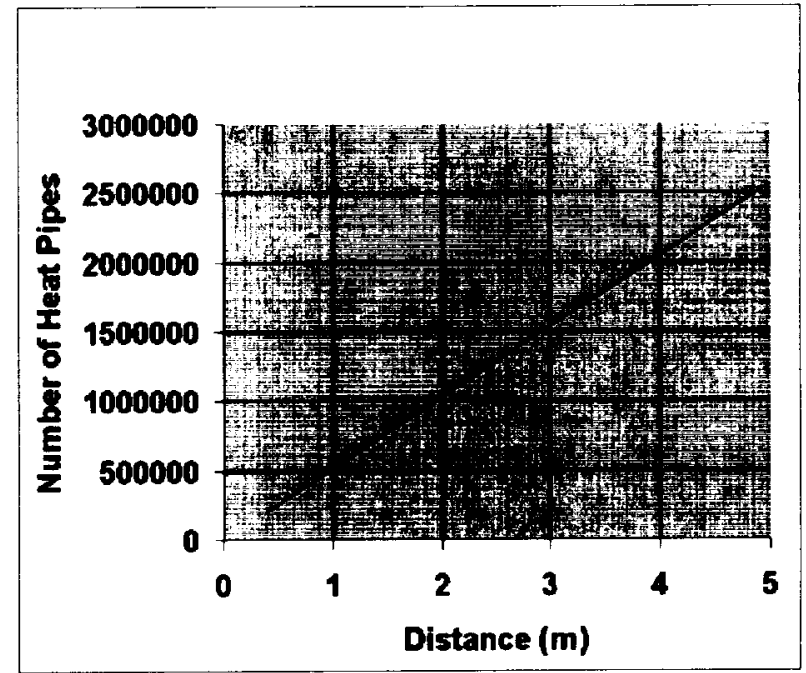

SUMMARY AND CONCLUSIONS

The thermal control system required for the solid state (butterstick) transmitter concept is much larger and heavier than that required for the klystrons concept. The reasons are as follows. First, in the klystrons concept, the efficiency of converting DC electricity to RF is $83 \%$. In the solid state concept, the efficiency of converting DC to RF is only $60 \%$. Therefore, the heat dissipation in the solid state concept is more than three times that in the klystrons concept. Second, the klystrons operate at much higher temperatures. A breakdown of the heat dissipation at the transmitters is as follows: $85 \%$ at $500^{\circ} \mathrm{C}, 10 \%$ at $300^{\circ} \mathrm{C}$, and $5 \%$ at $125^{\circ} \mathrm{C}$. The solid state electronics operate at about $100^{\circ} \mathrm{C}$. Since space is the heat sink for the waste heat, it is more effective to reject heat at higher temperatures.

In the baseline Dual or Single RF Reflector concept, and Integrated Symmetrical concept, there is a large radiator for the transmitter. Also, the diameter of the transmitter is $500 \mathrm{~m}$. To transport heat from some of the klystrons across the transmitters to the radiators, the distance is over $250 \mathrm{~m}$. If the average transport distance is $150 \mathrm{~m}$, then the mass of the heat transport system is 38,063 metric tons. It is larger than the mass of all the other SSP components combined. If solid state electronics are used, the mass is higher. In order to make the mass of the SSP design concepts acceptable, the distance between the transmitters and radiators must be minimized. If LHPs are used, the distance between the klystrons and radiators must be on the order of several meters. Space constructable heat pipe radiator is selected as the baseline because it is the most developed concept, and is a proven and reliable technology. The radiator area required for the klystrons concept is $74,470 \mathrm{~m}^{2}$. Its mass is 355 metric tons. In the Dual RF Reflector design concept, the

8 
radiator area required for each transmitter is 37,235 $\mathrm{m}^{2}$, which is $19 \%$ of that of the transmitter. In the Single RF Reflector concept and Integrated Symmetrical concept, there is only one transmitter, and the radiator area is $38 \%$ of that of the transmitter. The radiator area required for the solid state concept is $2,362,162 \mathrm{~m}^{2}$. It is twelve times the area of that of a transmitter. Its mass is 9,921 metric tons, which is $30 \%$ to $40 \%$ of the total mass budget for the SSP. For these reasons, the SSP concepts using klystrons are favored thermally. The concepts of using solid state are not practical.

The klystrons are scattered on the transmitters. Therefore, locating the radiators at the rear face of the transmitters alone is insufficient to reduce the mass of the heat transport system to within budget. The radiator must be divided into a cluster of small radiators, so that the heat transport distances between the klystrons and radiators are minimized. The area of each small radiator is on the order of $1 \mathrm{~m}^{2}$. The envelope of the radiators is about $1.5 \mathrm{~m}$ from the transmitter. Another configuration of accommodating a cluster of small radiators is to locate them at cylindrical envelopes behind the transmitter. The diameter of the cylindrical envelope closest to the transmitter is the largest, and that of the cylindrical envelope farthest from the transmitter is the smallest. With a special arrangement of the radiators, not only the front of the radiators has a good view to space, but also the rear can view space at least partially. The minimum distance between the transmitter and radiators is $1 \mathrm{~m}$, and the maximum distance is $10 \mathrm{~m}$. The height of the radiators is about $0.3 \mathrm{~m}$, and the area is about $1 \mathrm{~m}^{2}$. If the distance between the transmitters and radiators is $1.5 \mathrm{~m}$ or less, CCHPs are acceptable for heat transport. If the distance exceeds $1.5 \mathrm{~m}$, LHPs are needed.

\section{REFERENCES}

1. Glaser, P. E., "Power from the Sun: Its Future,"Science, Vol. 162, Nov. 1968, pp.857886.

2. Williams, J. R., "Geosynchronous Satellite Solar Power," Astronautics and Aeronautics, Dec. 1975, pp. 46-49.

3. Glaser, P. E., "Evolution of the Satellite Solar Power Station (SSPS) Concept," J. of Spacecraft, Vol. 13, Sep. 1976, pp. 573-576.

4. Carrington, C., et al., Dual RF Reflector Abacus Concept, Marshall Space Flight Center, Huntsville, AL, Oct. 1999.

5. Carrington, C., et al., Single RF Reflector Abacus Concept, Marshall Space Flight Center, Huntsville, AL, Nov. 1999.
6. Perkinson, D., et al., Integrated Symmetrical Concept, Marshall Space Flight Center, Huntsville, AL, Nov. 1999.

7. Perkinson, D., et al., Integrated Symmetrical Concept, Marshall Space Flight Center, Huntsville, AL, Feb. 2000.

8. Juhasz A. J. and Peterson, G. P., Review of Advanced Radiator Technologies for Spacecraft Power Systems and Space Thermal Control, NASA Technical Memorandum 4555, June 1994.

9. Ku, J., Operating Characteristics of LHPs, SAE Technical Paper Series 1999-01-2007.

10. Kaya, T. and $\mathrm{Ku}, \mathrm{J}$., A Parametric Study of Performance Characteristics of LHPs, SAE Technical Paper Series 1999-01-2006.

11. Kaya, T. and $\mathrm{Ku}, \mathrm{J}$., Ground Testing of LHPs for Spacecraft Thermal Control, AIAA Paper 993447.

12. Dunn, P. and Reay, D. A., Heat Pipes, Third Ed., Pergamon Press, 1982.

13. Juhasz, A. J., Design Considerations for Lightweight Space Radiators Based on Fabrication and Test Experience with a Carbon-Carbon Composite Prototype Heat Pipe, NASA/TP-1998207427 , Oct. 1998. 
Table 1. Thermal Control Systems in SSP Concepts using Klystrons versus Solid State.

\begin{tabular}{|c|c|c|}
\hline & Klystrons & $\begin{array}{c}\text { Solid State } \\
\text { (Butterstick) }\end{array}$ \\
\hline RF Output from Transmitters (GW) & 3.5 & 3.5 \\
\hline Efficiency of Converting DC to RF (\%) & 83 & 60 \\
\hline DC Input (GW) & 4.2169 & 5.8333 \\
\hline Waste Heat (GW) & 0.7169 & 2.3333 \\
\hline Ratio of Waste Heat to RF Output (GW/GW) & 0.2048 & 0.6667 \\
\hline Distribution of Waste Heat & $\begin{array}{c}85 \% \text { at } 500^{\circ} \mathrm{C} ; 10 \% \text { at } \\
300^{\circ} \mathrm{C} ; 5 \% \text { at } 125^{\circ} \mathrm{C}\end{array}$ & $100 \%$ at $\sim 100^{\circ} \mathrm{C}$ \\
\hline Size of Radiator $\left(\mathrm{m}^{2}\right)$ & 74,470 & $2,362,162$ \\
\hline Mass of Radiator (Metric Tons) @ $4.2 \mathrm{~kg} / \mathrm{m}^{2}$ & 197.2 & 9,921 \\
\hline Mass of Radiator Per Unit RF Output (Metric Tons/GW) & 164.3 & 2,835 \\
\hline Number of LHPs@ 2 kW per Loop with 33\% Redundancy & 169,440 & $1,551,800$ \\
\hline Material of Piping & $\begin{array}{c}\text { Stainless Steel } 300^{\circ} \mathrm{C} \mathrm{\&} \\
500^{\circ} \mathrm{C} ; \text { Aluminum } 125^{\circ} \mathrm{C}\end{array}$ & Aluminum \\
\hline Working Fluid & $\begin{array}{r}\text { Potassium } 500^{\circ} \mathrm{C} \\
\text { Thermex } 300^{\circ} \mathrm{C} \\
\text { Methanol } 125^{\circ} \mathrm{C}\end{array}$ & Ammonia \\
\hline LHP Technology & Liquid Metal Not Current & Current \\
\hline Distance Between Transmitters and Radiators (m) & 100 & 100 \\
\hline $\begin{array}{r}\text { Mass of LHPs @ } 2 \mathrm{~kW} \text { per Loop with 33\% Redundancy } \\
\text { (Metric Tons) }\end{array}$ & 68,840 & 89,300 \\
\hline $\begin{array}{r}\begin{array}{r}\text { Mass of LHPs Per Unit Distance Between Transmitters and } \\
\text { Radiators (Metric Tons/m) }\end{array} \\
\end{array}$ & 688 & 893 \\
\hline Mass of LHPs Per Unit RF Output (Metric Tons/GW) & 19,657 & 25,510 \\
\hline $\begin{array}{r}\text { Mass of LHPs Per RF Output Per Unit Distance Between } \\
\text { Transmitters and Radiators (Metric Tons/GW/m) }\end{array}$ & 197 & 255 \\
\hline $\begin{array}{l}\text { Mass of LHP Evaporator Per RF Output Per Unit Distance } \\
\text { Between Transmitters and Radiators (Metric Tons/GW/m) }\end{array}$ & $\sim 500$ & $\sim 280$ \\
\hline
\end{tabular}


Table 2. Mass of LHPs versus CCHPs for Thermal Control of Transmitters using Klystrons for Concept of Cluster of Small Radiators.

\begin{tabular}{|c|c|c|}
\hline & LHP & CCHP \\
\hline RF Output from Transmitters (GW) & 3.5 & 3.5 \\
\hline Efficiency of Converting DC to RF (\%) & 83 & 83 \\
\hline Waste Heat (GW) & 0.7169 & 0.7169 \\
\hline Ratio of Waste Heat to RF Output (GW/GW) & 0.2048 & 0.2048 \\
\hline Distribution of Waste Heat & $\begin{array}{c}85 \% \text { at } 500^{\circ} \mathrm{C} ; 10 \% \text { at } 300^{\circ} \mathrm{C} \text {; } \\
5 \% \text { at } 125^{\circ} \mathrm{C}\end{array}$ & $\begin{array}{c}85 \% \text { at } 500^{\circ} \mathrm{C} ; 10 \% \text { at } 300^{\circ} \mathrm{C} ; \\
5 \% \text { at } 125^{\circ} \mathrm{C}\end{array}$ \\
\hline Total Area of Cluster of Small Radiators $\left(\mathrm{m}^{2}\right)$ & $\begin{array}{c}84,580 \\
\left(37890 @ 500^{\circ} \mathrm{C} ; 14630 @ 300^{\circ} \mathrm{C} ;\right. \\
\left.32060 @ 125^{\circ} \mathrm{C}\right) \\
\end{array}$ & $\begin{array}{c}84,580 \\
\left(37,890 @ 500^{\circ} \mathrm{C} ;\right. \\
\left.14630 @ 300^{\circ} \mathrm{C} ; 32060 @ 125^{\circ} \mathrm{C}\right)\end{array}$ \\
\hline $\begin{array}{l}\text { Mass of Radiator with Embedded Heat Pipes (Metric } \\
\text { Tons) @ } 4.2 \mathrm{~kg} / \mathrm{m}^{2}\end{array}$ & $\begin{array}{c}355 \\
\left(159 @ 500^{\circ} \mathrm{C} ; 61 @ 300^{\circ} \mathrm{C} ;\right. \\
\left.135 @ 125^{\circ} \mathrm{C}\right)\end{array}$ & $\begin{array}{c}355 \\
\left(159 @ 500^{\circ} \mathrm{C} ; 61 @ 300^{\circ} \mathrm{C} ;\right. \\
\left.135 @ 125^{\circ} \mathrm{C}\right) \\
\end{array}$ \\
\hline Area of Radiator Per Unit RF Output $\left(\mathrm{m}^{2} / \mathrm{GW}\right)$ & $\begin{array}{c}24,170 \\
\left(10828 @ 500^{\circ} \mathrm{C} ; 4182 @ 300^{\circ} \mathrm{C} ;\right. \\
\left.9160 @ 125^{\circ} \mathrm{C}\right) \\
\end{array}$ & $\begin{array}{c}24,170 \\
\left(10828 @ 500^{\circ} \mathrm{C} ; 4182 @ 300^{\circ} \mathrm{C} ;\right. \\
\left.9160 @ 125^{\circ} \mathrm{C}\right) \\
\end{array}$ \\
\hline $\begin{array}{l}\text { Mass of Radiator Per Unit RF Output (Metric } \\
\text { Tons/GW) }\end{array}$ & $\begin{array}{c}101.5 \\
\left(45.5 @ 500^{\circ} \mathrm{C} ; 17.5 @ 300^{\circ} \mathrm{C} ;\right. \\
\left.38.5 @ 125^{\circ} \mathrm{C}\right)\end{array}$ & $\begin{array}{c}101.5 \\
\left(45.5 @ 500^{\circ} \mathrm{C} ; 17.5 @ 300^{\circ} \mathrm{C}\right. \\
\left.38.5 @ 125^{\circ} \mathrm{C}\right) \\
\end{array}$ \\
\hline Number of Heat Pipes with $33 \%$ Redundancy & $\begin{array}{c}476,740^{\circ} \\
\left(304680 @ 500^{\circ} \mathrm{C} ;\right. \\
\left.35845 @ 300^{\circ} \mathrm{C} ; 17925 @ 125^{\circ} \mathrm{C}\right)\end{array}$ & $\begin{array}{c}681,050^{\circ} \\
\left(435260 @ 500^{\circ} \mathrm{C} ;\right. \\
\left.51210 @ 300^{\circ} \mathrm{C} ; 25600 @ 125^{\circ} \mathrm{C}\right) \\
\end{array}$ \\
\hline Material of Piping @2.54 cm Outer Diameter & $\begin{array}{c}\text { Stainless Steel } 300^{\circ} \mathrm{C} \& 500^{\circ} \mathrm{C} \\
\text { Aluminum } 125^{\circ} \mathrm{C} \\
\end{array}$ & $\begin{array}{c}\text { Stainless Steel } 300^{\circ} \mathrm{C} \& 500^{\circ} \mathrm{C} ; \\
\text { Aluminum } 125^{\circ} \mathrm{C} \\
\end{array}$ \\
\hline Working Fluid & $\begin{array}{l}\text { Potassium } 500^{\circ} \mathrm{C} \text {; Thermex } \\
300^{\circ} \mathrm{C} \text {; Methanol } 125^{\circ} \mathrm{C}\end{array}$ & $\begin{array}{c}\text { Potassium } 500^{\circ} \mathrm{C} \text {; Thermex } \\
300^{\circ} \mathrm{C} \text {; Methanol } 125^{\circ} \mathrm{C} \\
\end{array}$ \\
\hline Heat Pipe Technology & Liquid Metal Not Current & Current, including Liquid Metal \\
\hline $\begin{array}{r}\text { Average Distance Between Klystrons and Radiators } \\
\text { (m) }\end{array}$ & $1 "$ & $1^{2+2 \pi}$ \\
\hline $\begin{array}{r}\text { Mass of Heat Pipes with 33\% Redundancy (Metric } \\
\text { Tons) }\end{array}$ & $\begin{array}{c}688 \\
\left(453 @ 500^{\circ} \mathrm{C} ; 52 @ 300^{\circ} \mathrm{C} ;\right. \\
\left.13 @ 125^{\circ} \mathrm{C}\right) \\
\end{array}$ & $\begin{array}{c}1,423 \\
\left(940 @ 500^{\circ} \mathrm{C} ; 111 @ 300^{\circ} \mathrm{C} ;\right. \\
\left.19 @ 125^{\circ} \mathrm{C}\right)\end{array}$ \\
\hline $\begin{array}{r}\text { Mass of per Unit Distance Between Transmitters and } \\
\text { Radiators (Metric Tons/m) }\end{array}$ & $\begin{array}{c}688 \\
\left(453 @ 500^{\circ} \mathrm{C} ; 52 @ 300^{\circ} \mathrm{C} ;\right. \\
\left.13 @ 125^{\circ} \mathrm{C}\right) \\
\end{array}$ & $\begin{array}{c}1,423 \\
\left(940 @ 500^{\circ} \mathrm{C} ; 111 @ 300^{\circ} \mathrm{C} ;\right. \\
\left.19 @ 125^{\circ} \mathrm{C}\right) \\
\end{array}$ \\
\hline $\begin{array}{r}\text { Mass of Heat Pipes Per Unit RF Output (Metric } \\
\text { Tons/GW) }\end{array}$ & $\begin{array}{c}147.8 \\
\left(130 @ 500^{\circ} \mathrm{C} ; 14 @ 300^{\circ} \mathrm{C} ;\right. \\
\left.4 @ 125^{\circ} \mathrm{C}\right) \\
\end{array}$ & $\begin{array}{c}306 \\
\left(269 @ 500^{\circ} \mathrm{C} ; 32 @ 300^{\circ} \mathrm{C} ;\right. \\
\left.5 @ 125^{\circ} \mathrm{C}\right) \\
\end{array}$ \\
\hline $\begin{array}{r}\text { Mass Heat Pipes Per Unit RF Output Per Unit Distance } \\
\text { Between Transmitters and Radiators (Metric } \\
\text { Tons } / \mathrm{GW} / \mathrm{m} \text { ) }\end{array}$ & $\begin{array}{c}147.8 \\
\left(130 @ 500^{\circ} \mathrm{C} ; 14 @ 300^{\circ} \mathrm{C}\right. \\
\left.4 @ 125^{\circ} \mathrm{C}\right) \\
\end{array}$ & $\begin{array}{c}306 \\
\left(269 @ 500^{\circ} \mathrm{C} ; 32 @ 300^{\circ} \mathrm{C}\right. \\
\left.5 @ 125^{\circ} \mathrm{C}\right) \\
\end{array}$ \\
\hline Mass of Evaporator (Metric Tons) & $\begin{array}{c}\sim 500 \\
\left(432 @ 500^{\circ} \mathrm{C} ; 54 @ 300^{\circ} \mathrm{C} ;\right. \\
\left.14 @ 125^{\circ} \mathrm{C}\right)\end{array}$ & Not Applicable \\
\hline
\end{tabular}

** Heat transport capacity not dependent on distance between transmitter and radiators.

*** Product of heat transport capacity and transport distance is $1.37 \mathrm{~kW}-\mathrm{m}$. 